\title{
Article
}

\section{Crystal Structure of the Epo1-Bem3 Complex for Bud Growth}

\author{
Jin Wang ${ }^{1,2,+}\left(\mathbb{C}\right.$, Lei $\mathrm{Li}^{1,+}$, Zhenhua Ming ${ }^{3}$, Lijie $\mathrm{Wu}^{4}$ and Liming Yan ${ }^{2, * \mathbb{C}}$ \\ 1 State Key Laboratory of Biotherapy, West China Hospital, Collaborative Innovation Center for Biotherapy, \\ Sichuan University, Chengdu 610041, China; wangjin9907@gmail.com (J.W.); lilei19890215@gmail.com (L.L.) \\ 2 Laboratory of Structural Biology and MOE Laboratory of Protein Science, School of Medicine, \\ Tsinghua University, Beijing 100084, China \\ 3 State Key Laboratory for Conservation and Utilization of Subtropical Agro-Bioresources, College of Life \\ Science and Technology, Guangxi University, Nanning 530000, China; zhming@gxu.edu.cn \\ 4 iHuman Institute, ShanghaiTech University, Shanghai 201210, China; wulj@sibcb.ac.cn \\ * Correspondence: yanlm@mail.tsinghua.edu.cn \\ + These authors contributed equally to this work.
}

\section{check for}

updates

Citation: Wang, J.; Li, L.; Ming, Z.; Wu, L.; Yan, L. Crystal Structure of the Epo1-Bem3 Complex for Bud Growth. Int. J. Mol. Sci. 2021, 22, 3812.

https://doi.org/10.3390/ijms22083812

Academic Editor: Shin-ichi Tate

Received: 15 March 2021

Accepted: 4 April 2021

Published: 7 April 2021

Publisher's Note: MDPI stays neutral with regard to jurisdictional claims in published maps and institutional affiliations.

Copyright: (c) 2021 by the authors. Licensee MDPI, Basel, Switzerland. This article is an open access article distributed under the terms and conditions of the Creative Commons Attribution (CC BY) license (https:// creativecommons.org/licenses/by/ $4.0 /)$.

\begin{abstract}
Tubules of the endoplasmic reticulum (ER) spread into the buds of yeast by an actin-based mechanism and, upon entry, become attached to the polarisome, a proteinaceous micro-compartment below the tip of the bud. The minimal tether between polarisome and cortical ER is formed by a protein complex consisting of Epo1, a member of the polarisome, Scs2, a membrane protein of the ER and Cdc42 guanosine triphosphatase-activating protein Bem3. Here, we report the crystal structure of a complex between Epo1 and Bem3. In addition, we characterize through the hydrogen/deuterium (H/D) exchange assay the interface between Scs2 and Epo1. Our findings provide a first structural insight into the molecular architecture of the link between cortical ER and the polarisome.
\end{abstract}

Keywords: budding yeast; polarisome; Epo1-Bem3; Ssc2; complex

\section{Introduction}

Polarized growth is crucial for various biological processes across yeast and filamentous fungi, which is achieved through the cytoskeleton-based directional transport of cargo to polarized domains [1]. As a result of its asymmetric growth and the polar delivery of organelles, the budding yeast, Saccharomyces cerevisiae, is considered to be the preferred model system for studying the mechanisms and molecules of polarized growth and faithful organelle inheritance in eukaryotic cells [1,2]. Rho GTPase Cdc42 is essential for the control of polarized growth during bud emergence, by recruitment of a yeast-specific complex called the polarisome, which is comprised of formin Bni1, nucleation-promoting factor (NPF) Bud6, Pea2, scaffolding protein Spa2 and receptor protein Epo1 [2-4]. During budding, Cdc42 also initiates the formation of a physical diffusion barrier at the neck, comprising septins, which compartmentalizes the bud plasma membrane (PM) from the mother $[5,6]$. However, distinct and not fully characterized protein complexes organize the contact sites between the PM and the endoplasmic reticulum.

Bem3 localizes to the sites of polarisome growth through its C-terminal Rho GTPaseactivating protein domain, which negatively regulates a Rho-type GTPase Cdc42 [7-9]. This domain is preceded by a lipid-binding pleckstrin homology (PH) domain, a PX (phox) domain and an N-terminal region that harbors a predicted coiled-coil domain $[8,10,11]$. A previous study showed that the $\mathrm{N}$-terminal coiled-coil domain of Bem3 interacts directly with the C-terminal coiled-coil domains of Epo1, which is a new member of the polarisome [2,12], suggesting a novel role for the polarisome in linking Bem3 to its functional target, Cdc42, during the budding process.

Scs2 is a homolog of mammalian synaptobrevin-associated protein, which is a conserved integral ER protein and a component of a lipid-sensing complex [12,13]. Scs2 serves as anchors to the ER for cytoplasmic proteins (including Opi1p), through a conserved motif 
known as FFAT, two phenylalanines (FF) in an acidic tract [14-16]. Scs2 also contributes to the tethering of the ER to the septins and to the robust inheritance of the cER, in that its single deletion already leads to a severe reduction in the number of cER-PM contact sites and an up-regulated unfolded protein response $[12,14,16,17]$. Epo1, which was founded to be the PM-located receptor for Scs2, can promote cER tethering at sites of polarized growth [2,12]. In budding yeast, there exists an Scs2-Epo1-Bem3 polarisome complex that is required to keep ER tubules or the PM-attached cER close to the tip of the bud during tip growth. The Epo1-Scs2 connection might pull the cER actively into the bud, and then the connection between Epo1 and Scs2 is dissolved during the M phase (Mitosis phase) of the cell cycle [2]. Whether and how Epo1 assists Scs2 in its newly discovered roles as an ER-septin tether and in spindle positioning remain open questions for future experiments.

To investigate the mechanism by which Epo1 anchors cER to the bud tip in yeast, we determine the X-ray structure of the C-terminal coiled-coil domains 2, 3 and 4 of Epo1 (named Epo1 ${ }^{\mathrm{CC} 2-\mathrm{CC} 4}$ ) in complex with the N-terminal coiled-coil domain of Bem3 (named $\mathrm{Bem} 3^{\mathrm{CC} 1}$ ). The structure reveals that the Bem $3^{\mathrm{CC} 1}$ domain forms a homodimer to bind four Epo1 ${ }^{\mathrm{CC} 2-\mathrm{CC} 4}$ molecules, with two CC3 domains of Epo1 providing an interface for binding to each Bem3 ${ }^{\mathrm{CC} 1}$. Moreover, through $\mathrm{H} / \mathrm{D}$ exchange assay, we determine that the $\mathrm{N}$-terminus 12 residue of Scs2 is responsible for binding to Epo1. Thus, Epo1 serves as a key receptor link between Scs2 and Bem3.

\section{Results}

\subsection{Bem3-Epo1 Complex Is a Hexamer}

The N-terminal coiled-coil domain of Bem3 was previously reported to interact directly with the C-terminal domain of Epo1 [2] (Figure 1A). We started with the co-expression of the N-terminal domain of Bem3 (residue 1-99, CC1 domain) and the C-terminal domain of Epo1 (residue 746-943, CC2-CC4 domain) in E. coli BL21(DE3) cells, and purified the Bem3-Epo1 complex using size-exclusion chromatography. The fractions were analyzed using SDS-PAGE, which showed that Bem3 ${ }^{\mathrm{CC} 1}$ and Epo1 ${ }^{\mathrm{CC} 2-\mathrm{CC} 4}$ can form a stable complex (Figure 1B). To determine the accurate mass of the Bem $3^{\mathrm{CC} 1}$ and Epo $1^{\mathrm{CC} 2-\mathrm{CC} 4}$ complex, we performed analytical gel filtration combined with MALS. Interestingly, while both $\mathrm{Bem} 3^{\mathrm{CC} 1}$ and $\mathrm{Epo} 1^{\mathrm{CC} 2-\mathrm{CC} 4}$ in isolation act as dimers in solution, the mixture of $\mathrm{Bem} 3^{\mathrm{CC} 1}$ and Epo1 ${ }^{\mathrm{CC} 2-\mathrm{CC} 4}$ eluted from MALS corresponded to a hexamer (about $100 \mathrm{kDa}$ molecular mass) (Figure 1C).

To determine the atomic structure of the protein complex between Bem3 ${ }^{\mathrm{CC} 1}$ and Epo1 ${ }^{\mathrm{CC} 2-\mathrm{CC} 4}$, we crystallized the Bem3 ${ }^{\mathrm{CC} 1}-\mathrm{Epo1}{ }^{\mathrm{CC} 2-\mathrm{CC} 4}$ complex and determined its structure to $3.5 \AA$ A resolution by X-ray crystallography (Figure 2A and Table S1). The model of the Epo1 ${ }^{\mathrm{CC} 2-\mathrm{CC} 4}-\mathrm{Bem} 3^{\mathrm{CC} 1}$ complex was built manually via several rounds of restrained individual atomic displacement parameter refinement, which allowed us to visualize the structure of the Epo1-Bem3 complex in detail. The final complex structure contained the heterologous hexamer of two Bem $3^{\mathrm{CC} 1}$ molecules and four Epo1 ${ }^{\mathrm{CC} 2}-\mathrm{CC} 4$ molecules in one asymmetric unit (Figure 2A), which was consistent with the aforementioned data obtained from MALS (Figure 1C), but the superposition of two Epo1 ${ }^{\mathrm{CC} 2-\mathrm{CC} 4}$ had obvious conformation changes (Figure S1). 
A

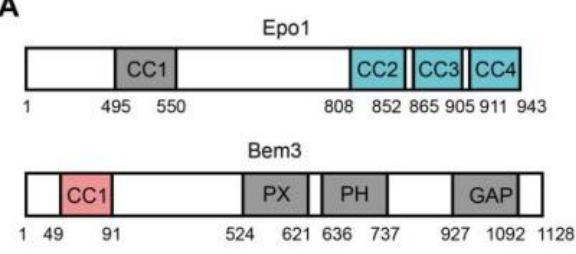

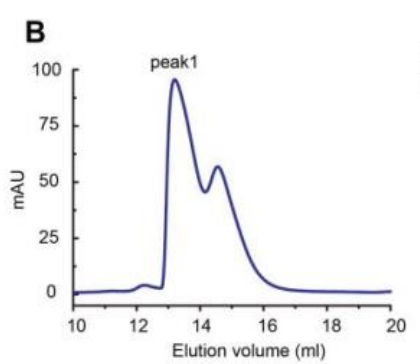
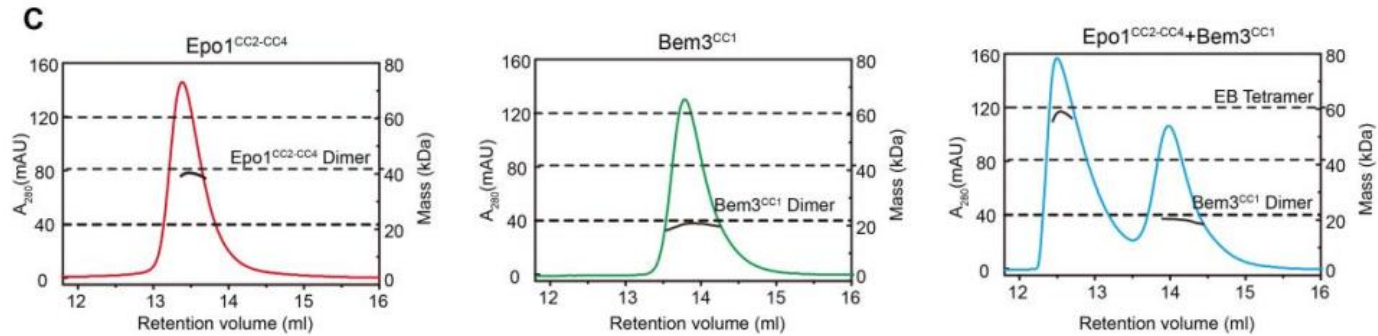

Figure 1. Functional domains and structures of Epo1 and Bem3. (A) Schematic diagram of domain structure of Epo1 and Bem3. Epo1 contains an N-terminal of unknown functional domain (residues 1-494) followed by four CC domains: CC1 is a predicted domain; CC2 to CC4 are side-by-side, with numbers indicating the amino acid positions of the start and endpoints of each domain. Bem3 contains CC1, PX, PH and GAP domains. (B) An elution profile shows the separation of the Epo1 ${ }^{\mathrm{CC} 2-\mathrm{CC} 4}$ and Bem $3^{\mathrm{CC} 1}$ complex from excess Bem3 using size-exclusion chromatography (left); confirmation of the purified Epo1 and Bem3 complex by Coomassie Brilliant Blue (CBB)-stained SDS/PAGE (right). (C) The sizes of the Epo1 $1^{\mathrm{CC} 2-\mathrm{CC} 4}$ and Bem $3^{\mathrm{CC} 1}$ complex are determined using MALS coupled with gel filtration. The data are representative of at least three repetitions.

\subsection{The Overall Structure of Epo1 $1^{\mathrm{CC} 2-C C 4}-\mathrm{Bem} 3^{\mathrm{CC} 1}$}

The Epo1 ${ }^{\mathrm{CC} 2-\mathrm{CC} 4}-\mathrm{Bem} 3^{\mathrm{CC} 1}$ complex is a heterologous hexamer with four Epo1 ${ }^{\mathrm{CC} 2-\mathrm{CC} 4}$ molecules and a Bem $3^{\mathrm{CC} 1}$ homodimer. The structure of Epo1 ${ }^{\mathrm{CC} 2-\mathrm{CC} 4}$ comprises three $\alpha$-helix, a CC2 helix (amino acids 821 to 851), a longer CC3 (amino acids 866 to 905) and a Cterminal CC4 (amino acids 912 to 939). Similar to Bem3 ${ }^{\mathrm{CC} 1}$, two Epo1 molecules are aligned in parallel and interact directly with each other to form homodimers; the observed buried area between the two promoters is $3522 \AA^{2}$. Two Epo1 homodimers located at the two sides of the Bem 3 homodimer finally assemble into a heterologous hexamer (Figure 2A).

The complex structure reveals that the two Epo1 homodimers interacted with each other via two interfaces. In the first interface, residue $S 837$ from Epo1 $\alpha 1$ stabilized $\alpha 1^{\prime}$ by forming hydrogen bonds with S837, E841 and $\alpha 2$ S879 formed a hydrogen bond with $\alpha 2$ ' Q844, while $\alpha 2$ K877 and $\alpha 1$ E841 formed a salt bridge (Figure 2B). The second region of intermolecular interactions was that of L924, I928 and I935 forming several hydrophobic interactions, which were buttressed by a salt bridge between $\alpha 3$ D932 and $\alpha 3^{\prime}$ R931 (Figure 2C). Moreover, Epo1 ${ }^{\mathrm{CC} 2-\mathrm{CC} 4}$ was a highly conserved cross-species (Figure 2D). 
A
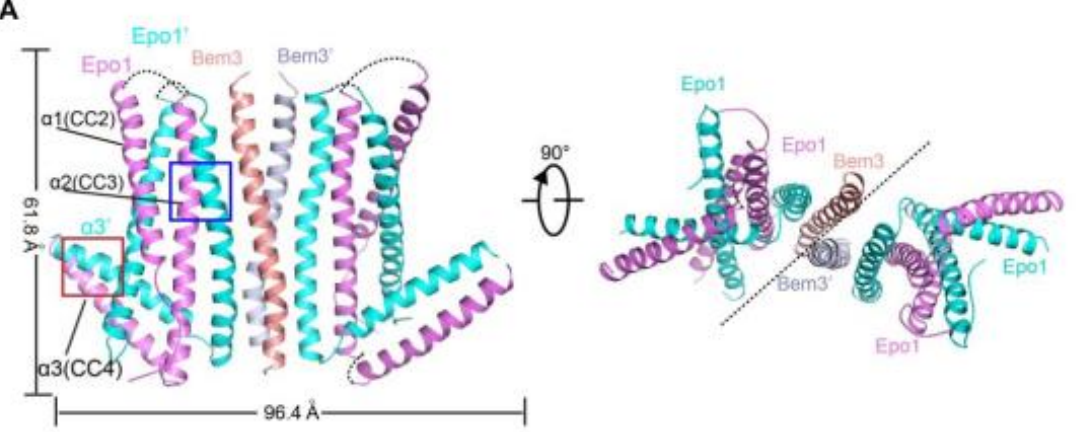

B

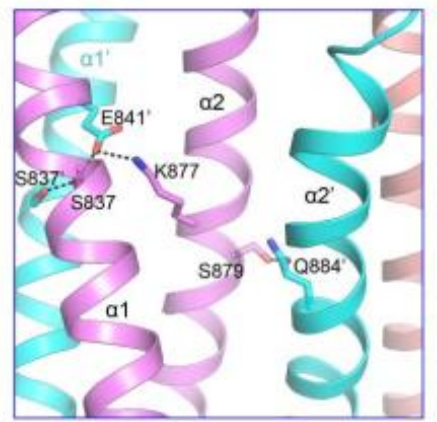

C

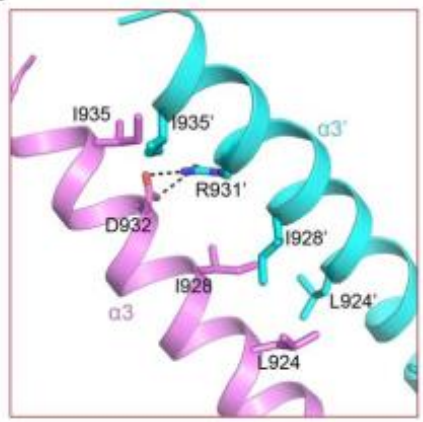

D

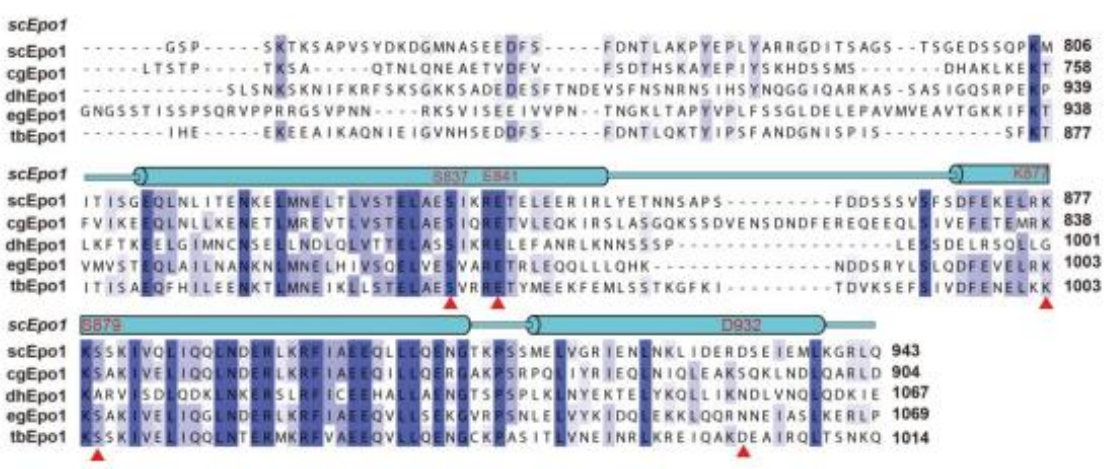

Figure 2. Structure of the Epo1 and Bem 3 complex. (A) Epo1 and Bem3 form the hexamer structure in the asymmetric unit, one Bem3 in complex with an Epo1 homodimer and two trimers side-by-side to form a heterologous hexamer; two promoters of Epo1 are colored violet and cyan, respectively. The Bem3 dimers show in the colors salmon and light blue (Bem3 and Bem $\left.3^{\prime}\right)$. (B) The CC2 dimer interface of Epo1 is shown as sticks with the key residues highlighted. (C) The interface of the Epo1 CC4 dimer. (D) The sequence alignment of scEpo1 and different species are conserved and similar residues are highlighted with blue and light blue; residues involved in the CC3 dimer interface are indicated by a red triangle. "sc", "cg", " $\mathrm{dh}^{\prime}$, , eg" and "tb" represent Saccharomyces cerevisiae, Candida glabrata, Debaryomyces hansenii, Eremothecium gossypii and Tetrapisispora blattae, respectively.

\subsection{Interaction of Epo1 ${ }^{\mathrm{CC} 2-\mathrm{CC} 4}-\mathrm{Bem} 3^{\mathrm{CC} 1}$}

As mentioned above, Bem3 formed a homodimer mainly via its CC1 helices; CC1 and $\mathrm{CC}^{\prime}$ form the parallel contents between the coiled-coil dimer (Figures 2A and 3A). The Bem $3^{\mathrm{CC} 1}$ folded into a dimeric parallel coiled-coil that was $61.8 \AA$ long, with a buried solvent-assessable area of $914 \AA^{2}$ (Figure 3A). Mutations of Bem3 N56 and Y66A disrupted the Bem3 dimer (Figure $3 C$ ) and these parts constituted the primary interface for Bem3 bound to Epo1 (Figure 4A). The Epo1-Bem3 interface regions could be subdivided into a central compartment and a side compartment. The major interface, a hydrophilic region, comprised Epo1 $\alpha 2$ and $\alpha 2^{\prime}$ to form a zipper with Bem3, consisting mainly of hydrogen bonds, involving residues from Bem3 (K58, Q62 and E69), Epo1 $\alpha 2$ (E872 and R876) and $\alpha 2^{\prime}$ (Q888) (Figure 4A,B), and a salt bridge between E65 of Bem3 and K881 of the Epo1 
$\alpha 2^{\prime}$ helix (Figure 4B). The minor interface contained a local intermolecular hydrogen bond network, involving the side chains of three critical residues (Q906 of Epo1 $\alpha 2^{\prime}$, R84 and E85 of Bem3') and the carbonyl oxygen of Epo1 A899 (Figure 4C). In order to investigate the role of the above-described key residues involved in interactions between Epo1 ${ }^{\mathrm{CC} 2-\mathrm{CC} 4}$ and $\mathrm{Bem} 3^{\mathrm{CC} 1}$, we performed site-directed mutagenesis and a subsequent SPR experiment.

\section{A}

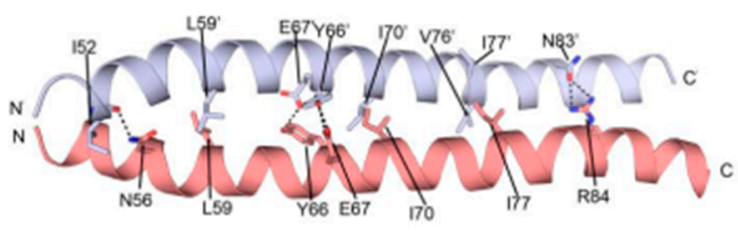

C
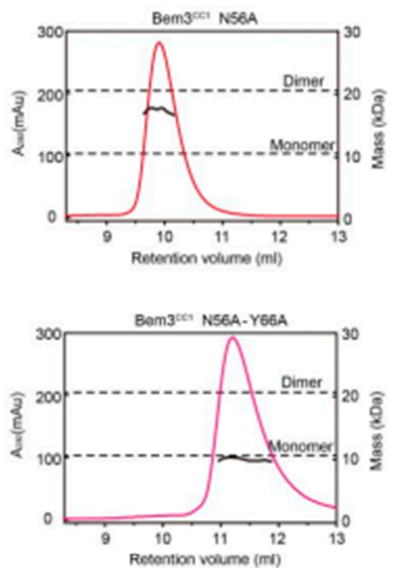

D

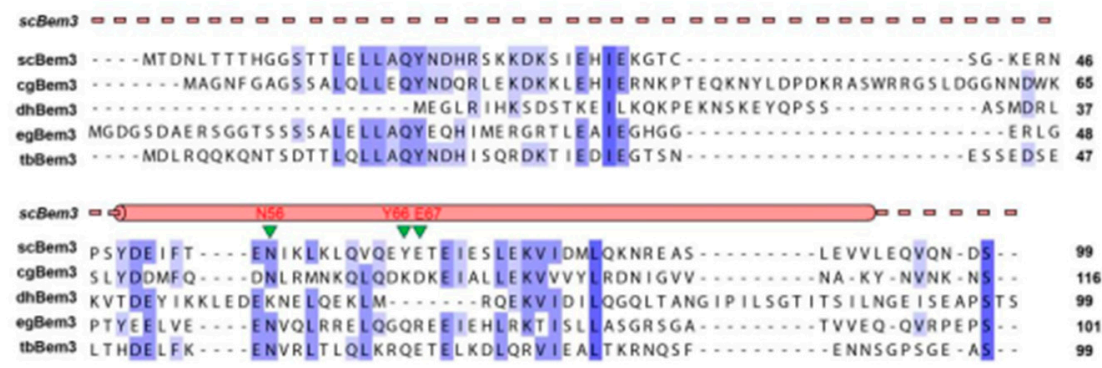

Figure 3. The dimer interaction of $\mathrm{Bem} 3^{\mathrm{CC} 1}$. (A) The interface residues between the $\mathrm{Bem} 3^{\mathrm{CC} 1}$ dimer. $(\mathbf{B}, \mathbf{C})$ The sizes of wild-type $(\mathrm{wt}) \mathrm{Bem} 3^{\mathrm{CC} 1}$ (theoretical molecular mass $11.39 \mathrm{kDa}$ ) and some key residue mutants were determined by MALS coupled with gel filtration. The estimated molecular masses are shown on the right axis. (D) Sequence alignment of Bem3 from different species: Saccharomyces cerevisiae (sc), Candida glabrata (cg), Debaryomyces hansenii (dh), Eremothecium gossypii (eg) and Tetrapisispora blattae (tb). The scBem 3 are numbered and aligned, while the secondary structures of Bem3 are labeled on top.

Consistent with our structural observations, a mutation of K881 disrupted the interactions between Epo1 and Bem3, while Q884A still maintained the stable interaction (Figure 4D). In addition, we tested the binding of Bem3 mutants to Epo1 using SPR, and found that the single-substitution of R84A, as well as inter-domain hydrogen bond network disruption, severely attenuated the interactions between Bem3 and Epo1 (Figure 4D). 
A

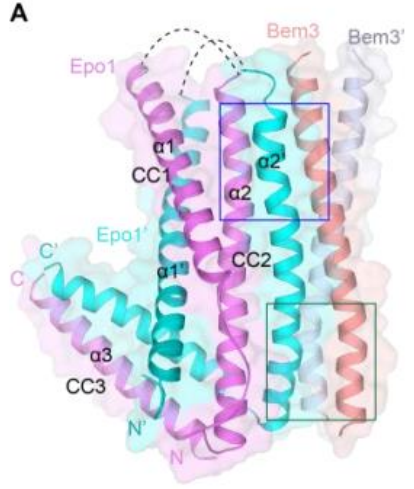

B

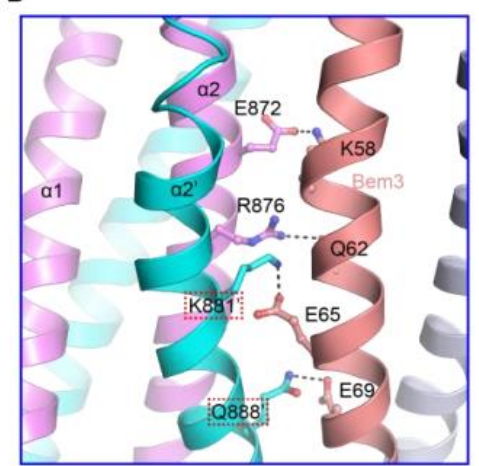

c

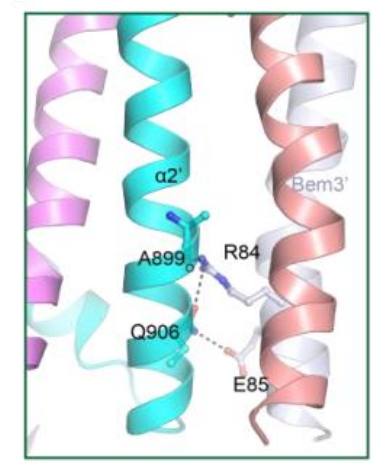

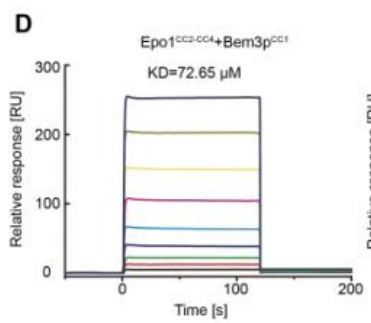
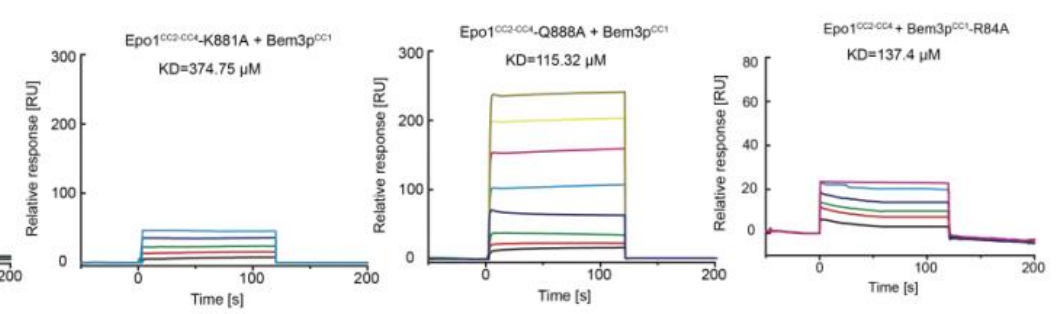

Figure 4. Heterologous interaction of Epo1 and Bem3. (A) Specific interaction between Epo1 and Bem3, with key regions boxed. (B,C) CC3 of two Epo1 present at the interaction surface with Bem3-CC; a stick representation of the key residue is shown. (D) The specific interaction between Bem3-CC and different Epo1-CC (WT and mutant) is characterized by SPR. Epo1-CC is seen binding to Bem3, Epo1-CC-K881A to Bem3, Epo1-CC Q88A to Bem3 and Epo1-CC R84A to Bem3.

\subsection{The Stimulation of Interaction between Epo1 and Scs2 by Bem3}

To explore the interaction between Epo1 and Scs2, we used the RED-tris-NTA fluorescent dye-labeled Scs2 to check binding using microscale thermophoresis (MST). $10 \mu \mathrm{L}$ of labeled Scs 2 was added to different concentration gradients of Epo1 ${ }^{\mathrm{CC} 2-\mathrm{CC} 4}$, Bem3 ${ }^{\mathrm{CC} 1}$ or Epo1 ${ }^{\mathrm{CC} 2-\mathrm{CC} 4}-\mathrm{Bem} 3^{\mathrm{CC} 1}$ complex. Upon inspection of the thermodynamic data, we found that Scs2 bound to Epo1 with a dissociation constant $\left(K_{\mathrm{d}}\right)$ of approximately $170 \mu \mathrm{M}$. While, in the presence of Bem3, the $K_{d}$ value shifted towards a lower value of $120 \mu \mathrm{M}$, suggesting that Bem3 could stimulate the interaction of Epo1 and Scs2. In the control experiment, Scs2 showed no detectable binding to Bem 3 under the same assay conditions (Figure 5A).

To further define the binding property of Scs2, we took advantage of the NMR titration method. NMR-monitored chemical shift titrations are considered to be an excellent means of studying weak protein-protein interactions. Therefore, we used the overlay of the ${ }^{1} \mathrm{H}^{-15} \mathrm{~N}$ HSQC spectra to analyze the interaction between Scs2 and Epo1. Comparison of the $2 \mathrm{D}^{1} \mathrm{H}^{-15} \mathrm{~N}$ HSQC spectra of Scs2 showed that the NH signal intensities significantly weakened as the concentration of added Epo1 increased from 5 to 10-fold (Figure 5C) and were enhanced in the presence of Bem3 (Figure 5D), though we rarely detected NH signal intensities decreasing for Scs2 and Bem3 (Figure 5A). Collectively, the changes of the NH signal intensities also indicated that Bem3 showed no directed binding to Scs2, but could increase the interaction of Scs2 bound to Epo1, obviously. 

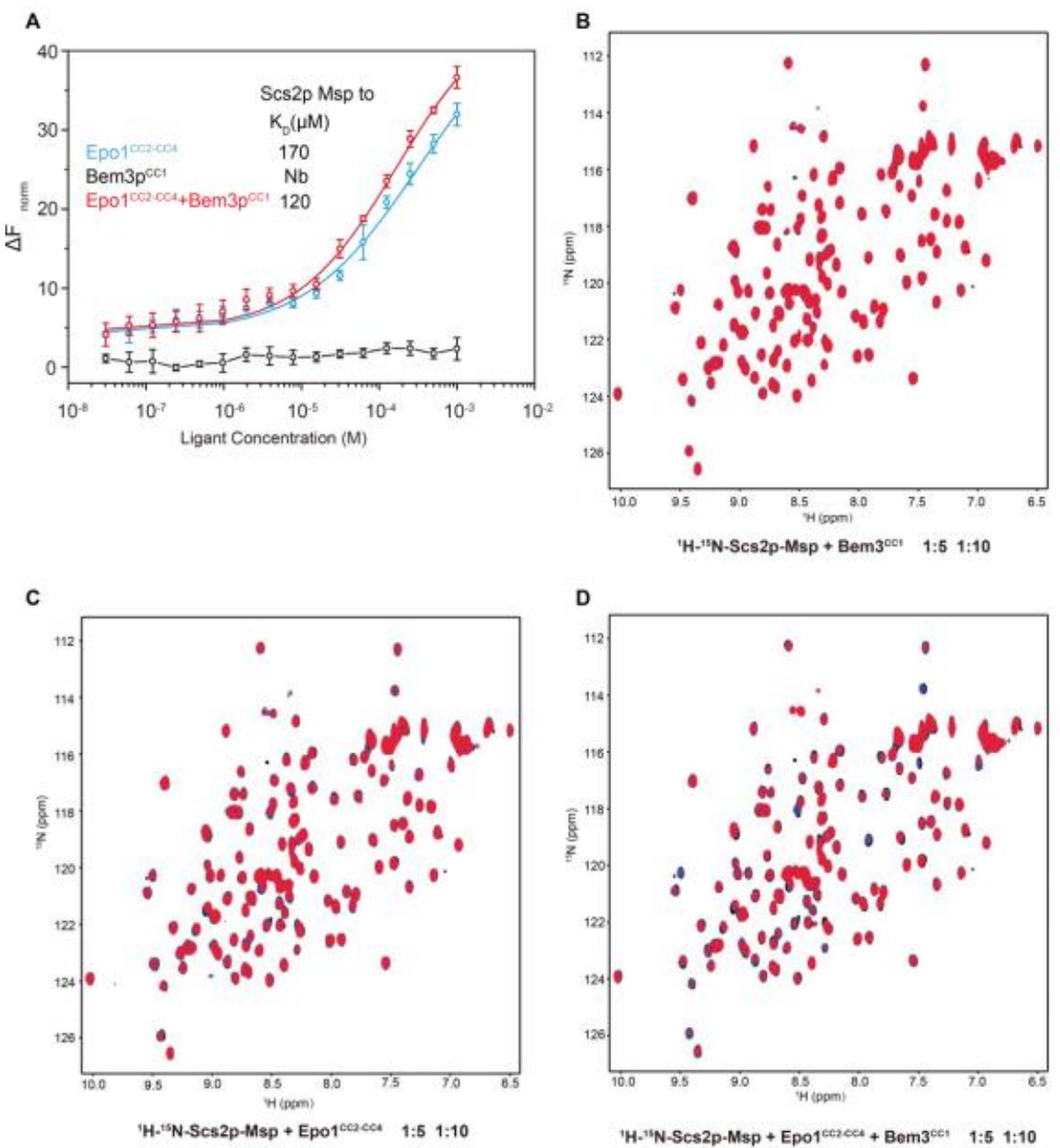

Figure 5. The analysis of Scs2-Msp interaction with Epo1 and Bem3. (A) $10 \mu \mathrm{L}$ of labeled N-His Scs2-Msp (100 nM) was added to a serial dilution of Epo1 (blue), Bem3 (black) or an EB complex (red) with an initial concentration of $2 \mathrm{mM}$ and applied in a buffer containing $20 \mathrm{mM}$ Tris- $\mathrm{HCl}, \mathrm{pH}$ 8.0, $150 \mathrm{mM} \mathrm{NaCl}, 4 \mathrm{mM} \mathrm{MgCl} 2$ and $0.05 \%$ Tween 20. Error bars showing SD were calculated from triplicate experiments. (B) An overlay of the ${ }^{1} \mathrm{H}_{-}{ }^{15} \mathrm{~N}$ HSQC spectra for $0.5 \mathrm{mM}$ of ${ }^{15} \mathrm{~N}$-labeled soluble Scs2p-Msp (1-128) in the absence (black) and in the presence of N-His-unlabeled Epo1 ${ }^{\mathrm{CC} 2-\mathrm{CC} 4}$ at a molar ratio of 1:5 (blue) and 1:10 (red). (C) An overlay of the ${ }^{1} \mathrm{H}^{-15} \mathrm{~N}$ HSQC spectra for $0.5 \mathrm{mM}$ of ${ }^{15} \mathrm{~N}$-labeled soluble Scs2-Msp (1-128) in the absence (black) and in the presence of N-His-unlabeled Bem $3^{\mathrm{CC} 1}$ at a molar ratio of 1:5 (blue) and 1:10 (red). (D) An overlay of the ${ }^{1} \mathrm{H}^{-15} \mathrm{~N}$ HSQC spectra for a $0.5 \mathrm{mM}$ of ${ }^{15} \mathrm{~N}$-labeled soluble Scs2-Msp (1128) in the absence (black) and in the presence of the Epo1 ${ }^{\mathrm{CC} 2-\mathrm{CC} 3}+\mathrm{Bem}^{\mathrm{CC} 1}$ complex at a molar ratio of 1:5 (blue) and 1:10 (red).

\subsection{Interaction between Scs2 and Epo1}

To date, there is no available Scs2 structure. To obtained detail structural information on the Epo1 binding regions in Scs2, we determined the crystal structure of Scs2 (residue 1-128). Scs2 crystallizes with one molecule in an asymmetric unit, but forms a symmetric dimer with a buried surface area of $200 \AA^{2}$ (Figure 6A). The interface is centered on a conserved sequence that mainly contains hydrophilic residues (T34, D95 and N97), with T34 forming hydrogen binds with D95 and N97 (Figure 6B). Dimeric interaction is essential for Scs2 binding to the F domain of ORP1 and Opi1p, which regulates the function of the complex to exchange sterol lipids between both organelles and stimulates the activity of the phosphoinositide phosphatase Sac1p, thereby controlling the levels of PI4P at the PM [18]. 
A

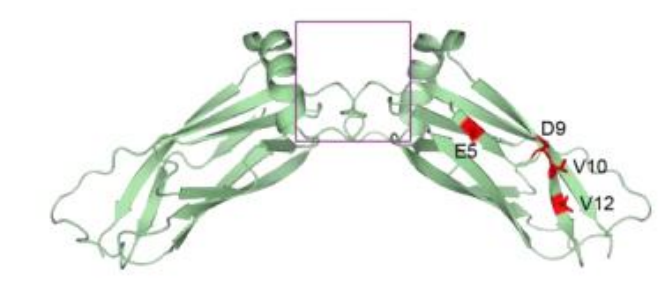

C

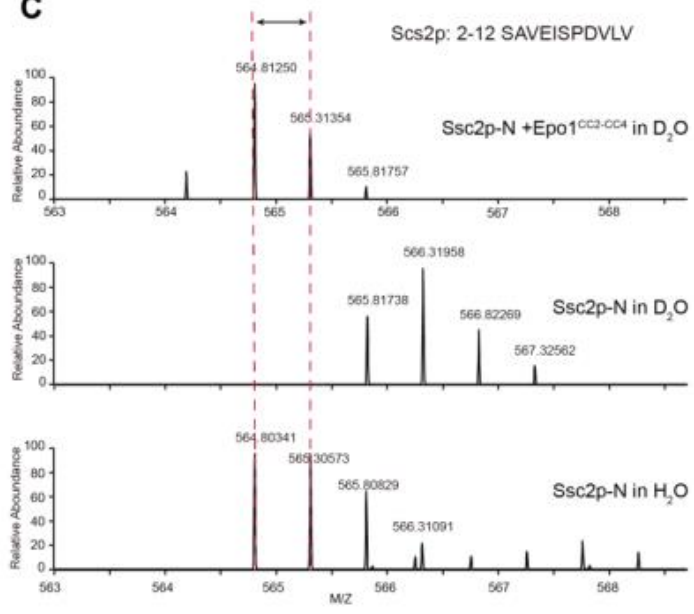

B

D
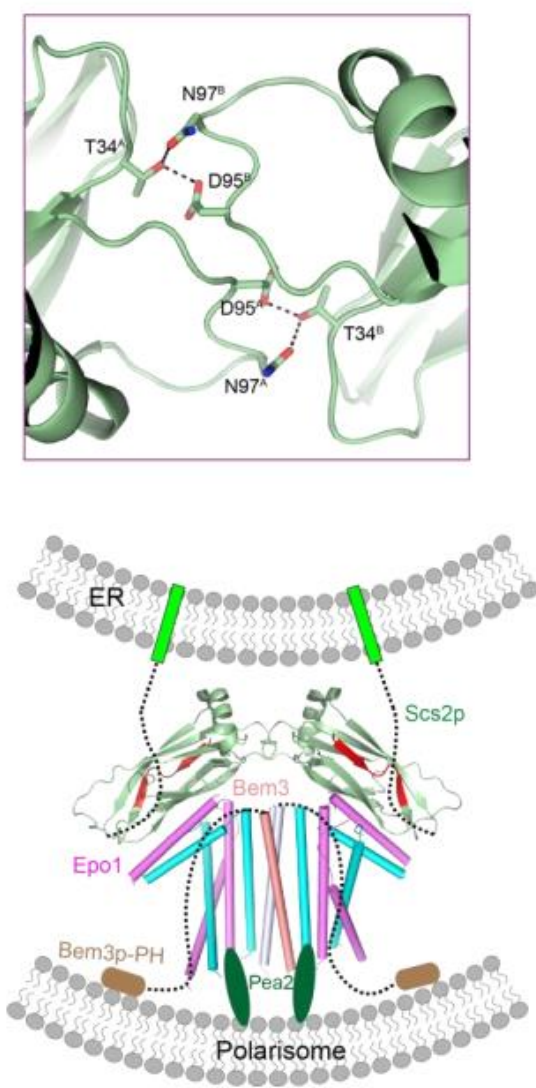

Figure 6. The model for the role of Epo1 and Bem3 in pulling the cER actively into the bud. (A) The interface between the Scs2 dimer; two promoters are labeled molecular A and molecular B. (B) Key regions are boxed and a stick representation of key residues is shown. (C) H/D exchange analysis of the Scs2-Epo1 complex; representative deuterium exchange mass spectra of the Scs2 peptide fragment. The peptide section of Scs2 from amino acids 2-12 is shown in red. (D) A model of the Scs2-Epo1-Bem3 polarisome complex keeping the PM-attached cER close to the tip of the bud during tip growth. Scs2 transmembrane domains are shown as green, while the Bem3 PH domain for binding the PM of polarisome is colored brown.

To address how Epo1 functions as a receptor to bind Scs2, we incubated Scs2 with an eight-fold molar excess of Epo1. A peptide that emerged from us analyzing the results of the H/D change assay indicated that the N-terminal region of Scs2 (amino acids 2-12) may have been involved in the interaction with Epo1. Detailed peptide sequence analysis revealed that Scs2 may present two regions of contact with Epo1, a hydrophilic region in E5-D9 and a hydrophobic region in V10-V12 (Figure 6C).

\subsection{The Model for the Role of Epo1 and Bem3 in Pulling the cER Actively into the Bud}

To envision how an Epo1 and Bem3 complex could participate in pulling the cER actively into the bud, we attempted to infer the interaction model between Epo1-Bem 3 and Scs2. Scs2 with a C-terminal transmembrane domain is localized to the sites of polarized growth. When yeast grows to form the bud, the Scs2 becomes localized to tubular ER, and tubular ER invades the yeast bud along actin cables [2,12].

Bem3, a GAP for Cdc42, is localized to the site of polarized growth. The Bem3 dimer is mediated by an $\mathrm{N}$-terminal coiled-coil domain, while the $\mathrm{PH}$ domain of Bem3 is responsible for binding to the membrane of the polarized cell tip. Epo1 can form a dimer that binds a molecule of Bem3 to form Epo1-Bem3, a hexamer, and meanwhile, Epo1 possesses the ability to act as a receptor that recruits Scs 2 by binding to its $\mathrm{N}$-terminal domain. Previous studies have shown that Pea2 binding sites are also located on the CC2 of Epo1; we, therefore, speculate that Bem 3 together with Pea2 recruits Epo1 into the polarisome. 


\section{Discussion}

Epo1 proteins contain four coiled-coil (CC) domains: CC1 located at its $\mathrm{N}$-terminus and $\mathrm{CC} 2$ to $\mathrm{CC} 4$ at its $\mathrm{C}$-terminus. In this study, we determined the CC2-CC4 to be in a complex with the Bem3 CC1 domain. Protein folding propensity analyses indicated that CC2-CC4 region formed a dimer with an "L" shaped structure, for novelty, in the polarisome complex. In order to identify the key Epo1 CC domain for interaction with Bem3, we isolated CC2, CC3, and CC2-CC3, respectively. While the CC2 and CC3 clones showed no expression, CC2-CC 3 could be expressed and bind with Epo1. Though Bem3 CC1 binding was not expected to interfere with the CC4 domain of Epo1, a deletion of CC4 would cause the Epo1-Bem3 interaction ability to decrease. This result suggested that the interaction between Bem3 and Epo1 might have been dependent on their coiled-coil domains. Indeed, as the CC1 domain of Bem3 docked on the CC3 surface of the Epo1 dimer, the overall Epo1-Bem3 structure may be relatively rigid for a hexamer. We did not find a detectable electron density between residues 746 and 808, indicating structural flexibility in this region.

Epo1 is critical in yeast bud development due to its function as a receptor that recruits Scs2 [2,12]. This article reports a key complex structure of Epo1-Bem3, which forms a specific contact to meet the specific demands of rapid membrane and cell wall extension at the cell tip. Specifically, this complex provides a platform for Scs2 interaction and contributes to the establishment of cell polarity, which are a fundamental processes in the life of a yeast bud.

In conclusion, our structure-function studies on the Epo1-Bem3-Scs2 complex reveal several important features. First, the N-terminus of Scs2 bound with Epo1 acts as a receptor of Scs2, and ORP1 and Opi1 also bind to Scs2 via the FFAT motif, which plays an important role in maintaining ER morphology. While we can only speculate on the dual function of $\mathrm{Scs} 2$, this is crucial for various biological processes. Second, the Bem $3^{\mathrm{CC} 1}$ dimer is the major determinant that is crucial for its polarized localization, as this segment can recruit the Epo1 protein in the absence of other structural elements of Bem3.

\section{Materials and Methods}

\subsection{Protein Preparation}

The C-terminal (746-943, named CC2-CC4) of Epo1 and N-terminal (1-99, named CC1) of Bem3 were amplified from the cDNA library (Saccharomyces cerevisiae BY4742) and cloned into the $\mathrm{pET}-28 \mathrm{~b}$ and $\mathrm{pET}-21 \mathrm{~b}$ vectors, respectively. Epo1 ${ }^{\mathrm{CC} 2-\mathrm{CC} 4}$ with an N-terminal hisSUMO tag and Bem3 ${ }^{\mathrm{CC} 1}$ with no tag were co-expressed in E. coli BL21(DE3) cells (Tiangen Biotech). Cells were grown at $37{ }^{\circ} \mathrm{C}$ and induced with $0.2 \mathrm{mM}$ isopropylthio- $\beta$-galactoside (IPTG) when the concentration of cells reached 0.8 according to the light absorption value $\left(\mathrm{OD}_{600}\right)$ detected by a UV-VIS spectrophotometer [19,20]. After induction at $16{ }^{\circ} \mathrm{C}$ for $18 \mathrm{~h}$, the cells were harvested, resuspended and lysed by sonication in buffer A $(20 \mathrm{mM}$ Tris- $\mathrm{HCl}, \mathrm{pH} 8.0,150 \mathrm{mM} \mathrm{NaCl}$ and $4 \mathrm{mM} \mathrm{MgCl}_{2}$ ). After centrifugation, the supernatant was loaded onto a Ni-affinity column equilibrated with buffer $\mathrm{A}$. The beads were washed with buffer A and the his-SUMO tag of Epo1 $1^{\mathrm{CC} 2-\mathrm{CC} 4}$ was removed by ULP protease at $4{ }^{\circ} \mathrm{C}$ overnight in buffer B (50 mM Tris, pH8.0, $150 \mathrm{mM} \mathrm{NaCl}$ and $5 \mathrm{mM} \beta$-Mercaptoethanol). Excess Epo1 ${ }^{\mathrm{CC} 2-\mathrm{CC} 4}$ was separated from the Epo1-Bem3 complex by Resource Q ion-exchange chromatography (GE Healthcare). Epo1 ${ }^{\mathrm{CC} 2-\mathrm{CC} 4}$ and Bem $3^{\mathrm{CC} 1}$ were cloned into a pET-22b vector, which contained the $6 \times$ His tag, for a pull-down assay. Both proteins were then purified by Hitrap $Q$ ion-exchange chromatography (GE Healthcare).

The selenomethionine (SeMet)-substituted protein was expressed in a minimal medium that inhibited methionine synthesis [21,22]. The Escherichia coli Transetta (DE3) cells were incubated overnight in Luria-Bertani (LB) medium at $37^{\circ} \mathrm{C}$ and harvested at $5000 \mathrm{rpm}$ $\left(10 \mathrm{~min}, 4^{\circ} \mathrm{C}\right.$ ). The pellet was inoculated in $1 \mathrm{~L}$ of M9 medium (supplemented with $100 \mathrm{mg} / \mathrm{L}$ kanamycin, $3 \%$ glucose) at $37^{\circ} \mathrm{C}$ until an $\mathrm{OD}_{600}$ of 0.6 was reached. $100 \mathrm{mg}$ each of Lys, Phe and Thr, and $50 \mathrm{mg}$ each of Ile, Leu, Val and SeMet were then added to the M9 medium and the mixture was further incubated for $15 \mathrm{~min}$ at $37^{\circ} \mathrm{C}$. After induction 
with $1 \mathrm{mM}$ IPTG, the cells were grown at $16{ }^{\circ} \mathrm{C}$ for an additional $16 \mathrm{~h}$. The SeMet-labeled protein was purified by the same procedure as described for the native protein.

\subsection{Crystallization, Data Collection and Structural Determination}

Crystallization was performed at $289 \mathrm{~K}$ using the hanging-drop vapor diffusion method. Each crystallization drop consisted of $1 \mu \mathrm{L}$ of protein solution $(10 \mathrm{mg} / \mathrm{mL})$ with an equal volume of the mother liquor equilibrated over $200 \mu \mathrm{L}$ of reservoir solution. Diffraction-quality crystals grew in $1.6 \mathrm{M}$ ammonium sulfate, $0.1 \mathrm{M} \mathrm{MES,} \mathrm{pH} \mathrm{6.5,} \mathrm{and}$ 10\% 1,4-Dioxane. A selenomethionine-derivatized Epo1-Bem3 complex crystalized under similar conditions. Single crystals were transferred to a cryoprotected buffer (reservoir solution and $20 \%$ glycerol) and flash-frozen in liquid nitrogen.

The dataset for selenomethionine derivatives of the Epo1-Bem3 complex and Scs2L86M were collected to $3.8 \AA$ and $2.0 \AA$, respectively, on a Beamline BL17 at Shanghai Synchrotron Radiation Facility (SSRF). Data were processed and scaled in the XDS program suite [23]. For the SeMet dataset, heavy atom searching, initial phase calculations and density modifications were performed with PHENIX [24]. The model was built manually with COOT [25] and subsequently refined with PHENIX. A summary of the final refinement statistics is shown in Table S1. Structural figures were prepared using the program PyMOL (https:/ / pymol.org/2/, (accessed on 19 August 2019)).

\subsection{Surface Plasmon Response (SPR) Assay}

All SPR experiments were carried out on a Biacore T200 (GE Healthcare, Uppsala, Sweden) with active temperature control at 25 following the manufacturer's protocols [26,27]. For protein immobilization, $100 \mu \mathrm{L}$ of $20 \mu \mathrm{g} / \mathrm{mL}$ Bem 3 in a sodium acetate buffer at $\mathrm{pH}$ 4.5 was prepared to be amino coupled onto channel 2 of a CM5 chip [28]. Target proteins were diluted in a running buffer (20 mM Hepes, $\mathrm{pH} 7.5,150 \mathrm{mM} \mathrm{NaCl}$ and $4 \mathrm{mM} \mathrm{MgCl} 2$ ) and flowed across immobilized Bem 3 for $240 \mathrm{~s}$ at a flow rate of $30 \mu \mathrm{L} / \mathrm{min}$ (association). The sample was replaced with the running buffer, followed by the disassociation of bound proteins for $480 \mathrm{~s}$ (disassociation). $5 \mathrm{mM} \mathrm{NaOH}$ buffer was used to regenerate the chip. The experimental data and fitting data were processed using GraphPad Prism.

\subsection{Binding Affinity Quantifications by Microscale Thermophoresis (MST)}

Binding affinity was detected by MST using Monolith NT.115 (Nanotemper Technologies). Purified Epo1 ${ }^{\text {cc2-cc4 }}$ was labeled with RED-tris-NTA fluorescent dye according to the instructions in the user manual (RED-tris-NTA second generation, Nano Temper \# MO-L018) and centrifuged at 14,000 rpm for $10 \mathrm{~min}$ to eliminate precipitates. A serial dilution of the target protein was applied in a buffer containing $20 \mathrm{mM}$ Tris- $\mathrm{HCl}, \mathrm{pH}$ 8.0, $150 \mathrm{mM} \mathrm{NaCl}, 4 \mathrm{mM} \mathrm{MgCl}$ and $0.05 \%$ Tween 20 . Affinity measurements were conducted in a Monolith NT.115 instrument. Data analysis of three independent experiments was performed using Nano Temper analysis software. The sigmoidal curves were normalized with the mean $\pm \mathrm{SD}$ of each data point, and $K_{\mathrm{d}}$ values were calculated.

\subsection{Multiangle Laser Light Scattering Analysis}

The static multiangle lighting scattering (MALS) detector DAWN HELEOS II (Wyatt) was used in conjunction with an analytical size-exclusion chromatography column (Superdex 200 10/300, GE Healthcare) to determine the distributions of the mass, size and composition (absolute molecular masses) of the applied samples. For each run, $100 \mu \mathrm{L}$ of the protein samples $(2-4 \mathrm{mg} / \mathrm{mL})$ were loaded into a column equilibrated with $20 \mathrm{mM}$ Tris ( $\mathrm{pH}$ 8.0), $150 \mathrm{mM} \mathrm{NaCl}$ and $4 \mathrm{mM} \mathrm{MgCl}_{2}$. For data analysis, the ASTRA software package version 6.1.2 was used (Wyatt) and all experiments were repeated at least three times.

\subsection{Hydrogen-Deuterium Exchange Mass Spectrometry (HDX-MS)}

HDX-MS is an established and powerful tool for protein-protein and protein-DNA interaction detection on a peptide level [29]. We coupled this approach with modern high- 
resolution mass spectrometry to measure the rates at which the amide hydrogen atoms of the protein backbone were exchanged with deuterium in a deuterated buffer, and could be localized to specific peptides within the primary structure, upon proteolytic digestion.

Solution-phase amide HDX experiments were carried out with a fully automated system, as described previously [29,30]. Scs2-Msp (final concentration was $6 \mathrm{mg} / \mathrm{mL}$ ) was premixed with a 1:5 molar excess of Epo1 ${ }^{\mathrm{CC} 2-\mathrm{CC} 4}$ and incubated for $2 \mathrm{~h}$ on ice before being subjected to HDX. $2 \mu \mathrm{L}$ of $6 \mathrm{mg} / \mathrm{mL}$ Scs2-Msp alone or the complex (1:5 molar mixture of Scs2-Msp and Epo1 $\left.{ }^{\mathrm{CC} 2-\mathrm{CC} 4}\right)$ was diluted with $18 \mu \mathrm{L}$ of a labeling buffer $(20 \mathrm{mM}$ Tris, $150 \mathrm{mM} \mathrm{NaCl}, 99 \% \mathrm{D}_{2} \mathrm{O}$ and $\left.\mathrm{pH} 7.6\right)$ at $25^{\circ} \mathrm{C}$ for $1 \mathrm{~min}$, and $20 \mu \mathrm{L}$ of ice-cold quench buffer (4M Guanidine hydrochloride, $200 \mathrm{mM}$ Citric acid and $100 \mathrm{mM}$ TECP in water solution at $\mathrm{pH} 1.8100 \% \mathrm{H}_{2} \mathrm{O}$ ) was added to quench the labeling. Quenched samples were then put on ice. Then, $2 \mu \mathrm{L}$ of $1 \mathrm{mg} / \mathrm{mL}$ pepsin solution was added for digestion. After $5 \mathrm{~min}$, the digested sample was centrifugated and placed into the auto-sampler of the Ultimate 3000 UPLC system (Thermo, CA, USA) for injection. $35 \mu \mathrm{L}$ of the sample was then loaded onto and separated by an ACQUITY UPLC $1.7 \mu \mathrm{m}$ BEH C18 $1.0 \mu \mathrm{m}$ column (Waters). The bound peptides were then gradient-eluted (1-100\% gradient of acetonitrile) over 19 min at a flow rate of $115 \mu \mathrm{L} / \mathrm{min}$. Both chromatographic mobile phases contained $1 \%(v / v)$ formic acid. The eluted peptides were then subjected to electrospray ionization coupled with a QExactive Orbitrap mass spectrometer (Thermo Scientific, Waltham, MA, USA). The hydrogen/deuterium exchange difference of each peptide between protein alone and protein with ligand was then manually checked.

\subsection{Heteronuclear Single Quantum Coherence (HSQC) Nuclear Magnetic Resonance (NMR)}

${ }^{1} \mathrm{H},{ }^{15} \mathrm{~N}$ and 2D HSQC NMR were conducted with a Bruker NMR spectrometer (800 MHz) using a $5 \mathrm{~mm}$ CPTCI $1 \mathrm{H}-13 \mathrm{C} / 15 \mathrm{~N} / \mathrm{D}$ Z-GRD probe. ${ }^{1} \mathrm{H}$ NMR spectra were obtained at $303 \mathrm{~K}$ in deuterated oxide $(99.9 \% \mathrm{D})$ as a solvent with a zgpr standard parameter set, with 16 scans and 2 dummy scans). ${ }^{15} \mathrm{~N}$ NMR and HSQC NMR experiments were obtained with respectively zgdc (14,368 scans and 2 dummy scans) and hsqcetqp (64 scans and 16 dummy scans) standard sets.

Supplementary Materials: The following are available online at https: / www.mdpi.com/article/10 .3390 /ijms22083812/s1, Figure S1, Comparison two promoter of Epo1 CC2-CC4; Figure S2, Sequence alignment of ScScs2 and other superfamily proteins. Table S1, Data collection and refinement statistics.

Author Contributions: L.Y. conceived the project and designed the experiments. J.W., L.L., Z.M. and L.W. performed the experiments. J.W. and L.Y. analyzed the data. L.Y. and J.W. wrote the manuscript. All authors discussed the experiments. All authors have read and agreed to the published version of the manuscript.

Funding: This work was supported by the National Program of Key Research Projects in China (2017YFC0840300).

Institutional Review Board Statement: Not applicable.

Informed Consent Statement: Not applicable.

Data Availability Statement: The structure were deposited into Protein Data Bank (PDB) with the accession numbers 6LP3 for Epo1-Bem3 complex, and 6LP4 for Scs2.

Acknowledgments: We thank Haiteng Deng and Meng Han of Tsinghua University for their assistance with mass spectrum analysis.

Conflicts of Interest: The authors declare no competing interest.

\section{References}

1. Pruyne, D.; Legesse-Miller, A.; Gao, L.; Dong, Y.; Bretscher, A. Mechanisms of polarized growth and organelle segregation in yeast. Annu. Rev. Cell Dev. Biol. 2004, 20, 559-591. [CrossRef]

2. Neller, J.; Dünkler, A.; Rösler, R.; Johnsson, N. A protein complex containing Epo1p anchors the cortical endoplasmic reticulum to the yeast bud tip. J. Cell Biol. 2015, 208, 71-87. [CrossRef] 
3. Nie, W.-C.; He, F.; Yuan, S.-M.; Jia, Z.-W.; Wang, R.-R.; Gao, X.-D. Roles of an N-terminal coiled-coil-containing domain in the localization and function of Bem3, a Rho GTPase-activating protein in budding yeast. Fungal Genet. Biol. 2017, 99, 40-51. [CrossRef]

4. Etienne-Manneville, S. Cdc42-The centre of polarity. J. Cell Sci. 2004, 117, 1291-1300. [CrossRef]

5. Dobbelaere, J.; Barral, Y. Spatial Coordination of Cytokinetic Events by Compartmentalization of the Cell Cortex. Science 2004, 305, 393-396. [CrossRef] [PubMed]

6. Luedeke, C.; Frei, S.B.; Sbalzarini, I.; Schwarz, H.; Spang, A.; Barral, Y. Septin-dependent compartmentalization of the endoplasmic reticulum during yeast polarized growth. J. Cell Biol. 2005, 169, 897-908. [CrossRef] [PubMed]

7. Knaus, M.; Pelli-Gulli, M.-P.; Van Drogen, F.; Springer, S.; Jaquenoud, M.; Peter, M. Phosphorylation of Bem2p and Bem3p may contribute to local activation of Cdc42p at bud emergence. EMBO J. 2007, 26, 4501-4513. [CrossRef]

8. Mukherjee, D.; Sen, A.; Boettner, D.R.; Fairn, G.D.; Schlam, D.; Valentin, F.J.B.; McCaffery, J.M.; Hazbun, T.; Staiger, C.J.; Grinstein, S.; et al. Bem3, a Cdc42 GTPase-activating protein, traffics to an intracellular compartment and recruits the secretory Rab GTPase Sec4 to endomembranes. J. Cell Sci. 2013, 126, 4560-4571. [CrossRef]

9. Aguilar, R.C.; Longhi, S.A.; Shaw, J.D.; Yeh, L.-Y.; Kim, S.H.; Schon, A.; Freire, E.; Hsu, A.; McCormick, W.K.; Watson, H.A.; et al. Epsin N-terminal homology domains perform an essential function regulating Cdc42 through binding Cdc42 GTPase-activating proteins. Proc. Natl. Acad. Sci. USA 2006, 103, 4116-4121. [CrossRef]

10. Burkhard, P.; Stetefeld, J.; Strelkov, S.V. Coiled coils: A highly versatile protein folding motif. Trends Cell Biol. 2001, 11, 82-88. [CrossRef]

11. Smith, G.R.; Givan, S.A.; Cullen, P.; Sprague, G.F., Jr. GTPase-Activating Proteins for Cdc42. Eukaryot. Cell 2002, 1, 469-480. [CrossRef]

12. Chao, J.T.; Wong, A.K.; Tavassoli, S.; Young, B.P.; Chruscicki, A.; Fang, N.N.; Howe, L.J.; Mayor, T.; Foster, L.J.; Loewen, C.J. Polarization of the Endoplasmic Reticulum by ER-Septin Tethering. Cell 2014, 158, 620-632. [CrossRef]

13. Loewen, C.J.R.; Gaspar, M.L.; Jesch, S.A.; Delon, C.; Ktistakis, N.T.; Henry, S.A.; Levine, T.P. Phospholipid Metabolism Regulated by a Transcription Factor Sensing Phosphatidic Acid. Science 2004, 304, 1644-1647. [CrossRef]

14. Loewen, C.J.; Roy, A.; Levine, T.P. A conserved ER targeting motif in three families of lipid binding proteins and in Opilp binds VAP. EMBO J. 2003, 22, 2025-2035. [CrossRef] [PubMed]

15. Nikawa, J.-I.; Murakami, A.; Esumi, E.; Hosaka, K. Cloning and Sequence of the SCS2 Gene, Which Can Suppress the Defect of IN01 Expression in an Inositol Auxotrophic Mutant of Saccharomyces cerevisiae. J. Biochem. 1995, 118, 39-45. [CrossRef]

16. Lowe, M.; Barr, F.A. Inheritance and biogenesis of organelles in the secretory pathway. Nat. Rev. Mol. Cell Biol. 2007, 8, 429-439. [CrossRef] [PubMed]

17. Manford, A.G.; Stefan, C.J.; Yuan, H.L.; MacGurn, J.A.; Emr, S.D. ER-to-Plasma Membrane Tethering Proteins Regulate Cell Signaling and ER Morphology. Dev. Cell 2012, 23, 1129-1140. [CrossRef]

18. Kaiser, S.E.; Brickner, J.H.; Reilein, A.R.; Fenn, T.D.; Walter, P.; Brunger, A.T. Structural Basis of FFAT Motif-Mediated ER Targeting. Structure 2005, 13, 1035-1045. [CrossRef]

19. Baneyx, F. Recombinant protein expression in Escherichia coli. Curr. Opin. Biotechnol. 1999, 10, 411-421. [CrossRef]

20. Jia, Z.; Yan, L.; Ren, Z.; Wu, L.; Wang, J.; Guo, J.; Zheng, L.; Ming, Z.; Zhang, L.; Lou, Z.; et al. Delicate structural coordination of the Severe Acute Respiratory Syndrome coronavirus Nsp13 upon ATP hydrolysis. Nucleic Acids Res. 2019, 47, 6538-6550. [CrossRef]

21. Hendrickson, W.A.; Horton, J.R.; LeMaster, D.M. Selenomethionyl proteins produced for analysis by multiwavelength anomalous diffraction (MAD): A vehicle for direct determination of three-dimensional structure. EMBO J. 1990, 9, 1665-1672. [CrossRef] [PubMed]

22. Doublié, S. Production of Selenomethionyl Proteins in Prokaryotic and Eukaryotic Expression Systems. Methods Mol. Biol. 2007, 363, 91-108. [CrossRef] [PubMed]

23. Kabsch, W. XDS. Acta Crystallogr. Sect. D Biol. Crystallogr. 2010, 66, 125-132. [CrossRef] [PubMed]

24. Afonine, P.V.; Grosse-Kunstleve, R.W.; Echols, N.; Headd, J.J.; Moriarty, N.W.; Mustyakimov, M.; Terwilliger, T.C.; Urzhumtsev, A.; Zwart, P.H.; Adams, P.D. Towards automated crystallographic structure refinement with phenix.refine. Acta Crystallogr. Sect. D Biol. Crystallogr. 2012, 68, 352-367. [CrossRef]

25. Emsley, P.; Cowtan, K. Coot: Model-building tools for molecular graphics. Acta Crystallogr. Sect. D Biol. Crystallogr. 2004, 60, 2126-2132. [CrossRef]

26. Pellequer, J.L.; Van Regenmortel, M. Measurement of kinetic binding constants of viral antibodies using a new biosensor technology. J. Immunol. Methods 1993, 166, 133-143. [CrossRef]

27. Douzi, B. Protein-Protein Interactions: Surface Plasmon Resonance. Methods Mol. Biol. 2017, 1615, $257-275$.

28. Johnsson, B.; Löfås, S.; Lindquist, G. Immobilization of proteins to a carboxymethyldextran-modified gold surface for biospecific interaction analysis in surface plasmon resonance sensors. Anal. Biochem. 1991, 198, 268-277. [CrossRef]

29. Chalmers, M.J.; Busby, S.A.; Pascal, B.D.; He, Y.; Hendrickson, C.L.; Marshall, A.G.; Griffin, P.R. Probing Protein Ligand Interactions by Automated Hydrogen/Deuterium Exchange Mass Spectrometry. Anal. Chem. 2006, 78, 1005-1014. [CrossRef] [PubMed]

30. Goswami, D.; Devarakonda, S.; Chalmers, M.J.; Pascal, B.D.; Spiegelman, B.M.; Griffin, P.R. Time Window Expansion for HDX Analysis of an Intrinsically Disordered Protein. J. Am. Soc. Mass Spectrom. 2013, 24, 1584-1592. [CrossRef] [PubMed] 